\title{
ON THE TOTAL EDGE AND VERTEX IRREGULARITYSTRENGTH OF SOME GRAPHS OBTAINED FROM STAR
}

\author{
Rismawati Ramdani ${ }^{1}$, A.N.M. Salman ${ }^{2}$, And Hilda Assiyatun ${ }^{2}$ \\ ${ }^{1}$ Department of Mathematics UIN Sunan Gunung Djati Bandung, \\ A.H. Nasution 105 Bandung, Indonesia, \\ rismawatiramdani@uinsgd.ac.id \\ ${ }^{2}$ Department of Mathematics, Institut Teknologi Bandung, \\ Ganesa 10 Bandung, Indonesia, \\ msalman@math.itb.ac.id, hilda@math.itb.ac.id
}

\begin{abstract}
Let $G=(V(G), E(G))$ be a graph and $k$ be a positive integer. A total $k$-labeling of $G$ is a map $f: V(G) \cup E(G) \rightarrow\{1,2, \cdots, k\}$. The edge weight $u v$ under the labeling $f$ is denoted by $w_{f}(u v)$ and defined by $w_{f}(u v)=f(u)+f(u v)+f(v)$. The vertex weight $v$ under the labeling $f$ is denoted by $w_{f}(v)$ and defined by $w_{f}(v)=$ $f(v)+\sum_{u v \in E(G)} f(u v)$. A total $k$-labeling of $G$ is called an edge irregular total $k$-labeling of $G$ if $w_{f}\left(e_{1}\right) \neq w_{f}\left(e_{2}\right)$ for every two distinct edges $e_{1}$ and $e_{2}$ in $E(G)$. The total edge irregularity strength of $G$, denoted by $\operatorname{tes}(G)$, is the minimum $k$ for which $G$ has an edge irregular total $k$-labeling. A total $k$-labeling of $G$ is called a vertex irregular total $k$-labeling of $G$ if $w_{f}\left(v_{1}\right) \neq w_{f}\left(v_{2}\right)$ for every two distinct vertices $v_{1}$ and $v_{2}$ in $V(G)$. The total vertex irregularity strength of $G$, denoted by $\operatorname{tvs}(G)$, is the minimum $k$ for which $G$ has a vertex irregular total $k$-labeling. In this paper, we determine the total edge irregularity strength and the total vertex irregularity strength of some graphs obtained from star, which are gear, fungus, and some copies of stars.
\end{abstract}

Keywords and Phrases: fungus graphs, gear graphs, the total edge irregularity strength, the total vertex irregularity strength, star graphs.

2010 Mathematics Subject Classification: 05C78. Received: 01-11-2018, accepted: 01-04-2019. 


\begin{abstract}
Abstrak. Misalkan $G=(V(G), E(G))$ adalah suatu graf dan $k$ adalah suatu bilangan bulat positif. Suatu pelabelan- $k$ total pada graf $G$ adalah suatu pemetaan $f: V(G) \cup E(G) \rightarrow\{1,2, \cdots, k\}$. Bobot dari sisi $u v$ berdasarkan pelabelan $f$ dinotasikan dengan $w_{f}(u v)$ dan didefinisikan sebagai $w_{f}(u v)=f(u)+f(u v)+f(v)$. Bobot dari titik $v$ berdasarkan pelabelan $f$ dinotasikan dengan $w_{f}(v)$ dan didefinisikan dengan $w_{f}(v)=f(v)+\sum_{u v \in E(G)} f(u v)$. Suatu pelabelan- $k$ total pada $G$ dikatakan pelabelan- $k$ total tak teratur sisi di $G$ jika $w_{f}\left(e_{1}\right) \neq w_{f}\left(e_{2}\right)$ untuk setiap dua sisi yang berbeda $e_{1}$ dan $e_{2}$ di $E(G)$. Nilai total ketakteraturan sisi dari $G$, dinotasikan dengan $\operatorname{tes}(G)$, adalah nilai $k$ terkecil sehingga $G$ memiliki suatu pelabelan- $k$ total tak teratur sisi. Suatu pelabelan- $k$ pada graf $G$ dikatakan suatu pelabelan- $k$ total tak teratur titik pada $G$ jika $w_{f}\left(v_{1}\right) \neq w_{f}\left(v_{2}\right)$ untuk setiap dua titik yang berbeda $v_{1}$ dan $v_{2}$ di $V(G)$. Nilai total ketakteraturan titik dari $G$, dinotasikan dengan $\operatorname{tvs}(G)$, adalah nilai $k$ terkecil sehingga $G$ memiliki suatu pelabelan- $k$ total tak teratur titik. Pada makalah ini, ditentukan nilai total ketakteraturan sisi maupun titik dari beberapa graf yang dibentuk dari graf bintang, yaitu graf gerigi, graf jamur, dan beberapa salinan dari graf bintang.
\end{abstract}

Kata kunci: graf jamur, graf gerigi, nilai total ketakteraturan sisi, nilai total ketakteraturan titik, graf bintang

\title{
1. INTRODUCTION
}

Let $G=(V(G), E(G))$ be a graph and $k$ be a positive integer. A total $k$ labeling of $G$ is a map $f: V(G) \cup E(G) \rightarrow\{1,2, \cdots, k\}$. A total $k$-labeling of $G$ is called an edge irregular total $k$-labeling of $G$ if for every two distinct edges $u v$ and $w x$ in $E(G)$, satisfy $w_{f}(u v) \neq w_{f}(w x)$ where $w_{f}(u v)=f(u)+f(u v)+f(v)$. The total edge irregularity strength of $G$, denoted by tes $(G)$, is the minimum $k$ for which $G$ has an edge irregular total $k$-labeling.

A research about determining the total edge irregularity strength was started by Bača et al. [1]. In the paper, they gave a lower bound and an upper bound on tes $(G)$ for arbitrary graph $G$. The result is given by Theorem 1.1.

Theorem 1.1. [1] Let $G=(V, E)$ be a graph with the vertex set $V$ and the edge set $E$. Then, $\left\lceil\frac{|E|+2}{3}\right\rceil \leq \operatorname{tes}(G) \leq|E|$.

In the same paper, Bača et al. [1] gave the exact value of tes $(G)$ for some graphs, two of them are path and cycle.The results are given in two theorems below.

Theorem 1.2. [1] Let $n$ be a positif integer and $P_{n}$ be a path with order $n$. Then, $\operatorname{tes}\left(P_{n}\right)=\left\lceil\frac{n+1}{3}\right\rceil$.

Theorem 1.3. [1] Let $n$ be a positif integer and $C_{n}$ be a cycle with order $n$. Then, $\operatorname{tes}\left(C_{n}\right)=\left\lceil\frac{n+2}{2}\right\rceil$.

Another result about tes $(G)$ was given by Siddiqui et al. in [9]. In the paper, they gave the exact value of $\operatorname{tes}(G)$ where $G$ is a disjoint union of sun graphs. Nurdin et al. in [3] gave the total edge irregularity strength of disjoint union of 
complete bipartite graphs $K_{2, n}$. The total edge irregularity strength of corona product of path with other graph was given by Nurdin et al. in [4].

Another labeling was introduced by Bača et al. [1] is total vertex irregular labeling. A total $k$-labeling of $G$ is called a vertex irregular total $k$-labeling of $G$ if $w_{f}\left(v_{1}\right) \neq w_{f}\left(v_{2}\right)$ for every two distinct vertices $v_{1}$ and $v_{2}$ in $V(G)$ where $w_{f}\left(v_{1}\right)=f\left(v_{1}\right)+\sum_{u v_{1} \in E(G)} f\left(u v_{1}\right)$. The total vertex irregularity strength of $G$, denoted by $\operatorname{tvs}(G)$, is the minimum $k$ for which $G$ has a vertex irregular total $k$ labeling. In the paper [1], Bača et al gave $\operatorname{tvs}(G)$ for some graphs $G$, one of them is complete graph with order $p$, denoted by $K_{p}$.

A lower bound on $\operatorname{tvs}(G)$ related to the minimum degree of $G$ was given by Nurdin et al in [2]. The result is given in Theorem 1.4.

Theorem 1.4. [2] Let $G$ be a graph with the minimum degree $\delta$. Then,

$$
\operatorname{tvs}(G) \geq \max \left\{\left\lceil\frac{\delta+n_{\delta}}{\delta+1}\right\rceil,\left\lceil\frac{\delta+n_{\delta}+n_{\delta+1}}{\delta+2}\right\rceil, \ldots,\left\lceil\frac{\delta+\sum_{i=\delta}^{\Delta} n_{i}}{\Delta+1}\right\rceil\right\},
$$

where $n_{i}$ be the number of vertices with degree $i$ for $i=\delta, \delta+1, \cdots, \Delta$.

In the different paper, Nurdin et al. [5] gave the total vertex irregularity strength of banana tree and quadrat tree. In [6], Nurdin et al. also gave the total vertex irregularity strength of caterpillar. In [7], Nurdin et al. determined the total vertex irregularity strength of disjoint union of paths. On the other hand, Wijaya et al. in [11] determined the total vertex irregularity strength of wheel, fan, sun, and friendship. In [8], Przybylo gave bounds of $\operatorname{tvs}(G)$ with provided order, minimum degree, and maximum degree of the graph. The total vertex irregularity strength of torodial grid $C_{m} \square C_{n}$ was given by Tong et al. in [10].

\section{MAIN RESULTS}

In this section, we determine the total edge and vertex irregularity strength of some graphs obtained from star, which are gear, fungus, and some copies of star. Those graphs have a vertex with the degree is far greater than other vertices. It is interesting to determine the total vertex irregular labeling of the graphs.

\subsection{On The Total Edge and Vertex Irregularity Strength of Gear}

In this subsection, we determine the exact value of the total edge and vertex irregularity strength of gear.

Let $n \geq 3$. Gear $G_{n}$ is a graph with the vertex set

$$
V\left(G_{n}\right)=\left\{u, v_{1}, v_{2}, \cdots, v_{n}, w_{1}, w_{2}, \cdots, w_{n}\right\}
$$

and the edge set

$$
E\left(G_{n}\right)=\left\{u v_{i}, v_{i} w_{i} \mid i=1,2, \cdots n\right\} \cup\left\{w_{i} v_{i+1} \mid i=1,2, \cdots n-1\right\} \cup\left\{w_{n} v_{1}\right\} .
$$


The theorem below gives the total edge irregularity strength of gear.

Theorem 2.1. Let $n \geq 3$ and $G_{n}$ be a gear with order $2 n+1$. Then,

$$
\operatorname{tes}\left(G_{n}\right)=n+1 \text {. }
$$

Proof. Gear $G_{n}$ has $3 n$ edges. From Theorem 1.1, we have a lower bound on $\operatorname{tes}\left(G_{n}\right)$ is $\left\lceil\frac{3 n+2}{3}\right\rceil=n+1$.

Next, we will show that an upper bound on $\operatorname{tes}\left(G_{n}\right)$ is $n+1$. Define a total labeling $f: V\left(G_{n}\right) \cup E\left(G_{n}\right) \rightarrow\{1,2, \ldots, n+1\}$ of $G_{n}$ as follows.

$$
\begin{aligned}
& f(u)=f\left(u v_{i}\right)=n+1 \quad \text { for } 1 \leq i \leq n \text {; } \\
& f\left(v_{i}\right)= \begin{cases}1 & \text { for } i=1 \\
2 i-2 & \text { for } 2 \leq i \leq\left\lfloor\frac{n}{2}\right\rfloor+1 \\
2(n-i)+3 & \text { for }\left\lfloor\frac{n}{2}\right\rfloor+2 \leq i \leq n\end{cases} \\
& f\left(w_{i}\right)= \begin{cases}2 i-1 & \text { for } 1 \leq i \leq\left\lceil\frac{n}{2}\right\rceil \\
2(n-i)+2 & \text { for }\left\lceil\frac{n}{2}\right\rceil+1 \leq i \leq n\end{cases} \\
& f\left(v_{i} w_{i}\right)= \begin{cases}1 & \text { for } i=1 \text { or }\left\lfloor\frac{n}{2}\right\rfloor+2 \leq i \leq n \\
2 & \text { for } 2 \leq i \leq\left\lfloor\frac{n}{2}\right\rfloor+1\end{cases} \\
& f\left(w_{i} v_{i+1}\right)= \begin{cases}1 & \text { for } 1 \leq i \leq\left\lfloor\frac{n}{2}\right\rfloor \\
2 & \text { for }\left\lfloor\frac{n}{2}\right\rfloor+1 \leq i \leq n-1\end{cases} \\
& f\left(w_{n} v_{1}\right)=2 .
\end{aligned}
$$

It can be seen that the maximum label used in the labeling above is $n+1$.

Next, from the labeling $f$, we have the weight of edges of $G_{n}$ as follows.

$$
\begin{aligned}
w_{f}\left(v_{i} w_{i}\right) & = \begin{cases}4 i-1 & \text { for } 1 \leq i \leq\left\lceil\frac{n}{2}\right\rceil \\
4(n-i)+6 & \text { for }\left\lceil\frac{n}{2}\right\rceil+1 \leq i \leq n ;\end{cases} \\
w_{f}\left(w_{i} v_{i+1}\right) & = \begin{cases}4 i & \text { for } 1 \leq i \leq\left\lceil\frac{n}{2}\right\rceil \\
4(n-i)+5 & \text { for }\left\lceil\frac{n}{2}\right\rceil+1 \leq i \leq n-1 ;\end{cases} \\
w_{f}\left(w_{n} v_{1}\right) & =5 ; \\
w_{f}\left(u v_{i}\right) & = \begin{cases}2 n+3 & \text { for } i=1 \\
2 n+2 i & \text { for } 2 \leq i \leq\left\lfloor\frac{n}{2}\right\rfloor+1 \\
2 n+2(n-i)+5 & \text { for }\left\lfloor\frac{n}{2}\right\rfloor+2 \leq i \leq n .\end{cases}
\end{aligned}
$$

The weight of the edges are adalah $3,4, \cdots, 3 n+2$ with there are no two edges with the same weight. So, we can conclude that $\operatorname{tes}\left(G_{n}\right)=n+1$.

The exact value of $\operatorname{tvs}\left(G_{n}\right)$ is given in the theorem below.

Theorem 2.2. Let $n \geq 3$ and $G_{n}$ be a gear with order $2 n+1$. Then,

$$
\operatorname{tvs}\left(G_{n}\right)= \begin{cases}3, & \text { for } n=3 \\ \left\lceil\frac{n+1}{2}\right\rceil & \text { for } n \geq 4\end{cases}
$$


Proof. Gear $G_{n}$ has $2 n+1$ vertices, which are $n$ vertices with degree $2, n$ vertices with degree 3 , and 1 vertex with degree $n$. So, by using Theorem 1.4, we have

$$
\begin{aligned}
\operatorname{tvs}(G) & \geq \max \left\{\left\lceil\frac{2+n}{2+1}\right\rceil,\left\lceil\frac{2+n+n}{2+2}\right\rceil,\left\lceil\frac{2+n+n+1}{n+1}\right\rceil\right\} \\
& =\max \left\{\left\lceil\frac{n+2}{3}\right\rceil,\left\lceil\frac{n+1}{2}\right\rceil, 3\right\} .
\end{aligned}
$$

Since $\max \left\{\left\lceil\frac{n+2}{3}\right\rceil,\left\lceil\frac{n+1}{2}\right\rceil, 3\right\}=\left\{\begin{array}{ll}3 & \text { for } n=3 \\ \left\lceil\frac{n+1}{2}\right\rceil & \text { for } n \geq 4,\end{array}\right.$ we have

$$
\operatorname{tvs}\left(G_{n}\right) \geq \begin{cases}3 & \text { for } n=3 \\ \left\lceil\frac{n+1}{2}\right\rceil & \text { for } n \geq 4\end{cases}
$$

Next, we will show that $\operatorname{tvs}\left(G_{n}\right) \leq\left\{\begin{array}{ll}3 & \text { for } n=3 \\ \left\lceil\frac{n+1}{2}\right\rceil & \text { for } n \geq 4\end{array}\right.$ Define a total labeling $f$ of $G_{n}$ as follows.

- For $n=3$,

$$
\begin{aligned}
f(u) & =3 ; f\left(v_{i}\right)=2 ; f\left(w_{i}\right)=1 \text { for } i \in\{1,2,3\} \\
f\left(v_{1} w_{1}\right) & =f\left(w_{1} v_{2}\right)=f\left(w_{3} v_{1}\right)=1 ; \\
f\left(v_{2} w_{2}\right) & =f\left(v_{3} w_{3}\right)=f\left(w_{2} v_{3}\right)=f\left(u v_{i}\right)=2 \text { for } i \in\{1,2,3\} .
\end{aligned}
$$

- For $n \geq 4$,

$$
\begin{aligned}
f(u) & =f\left(w_{i}\right)=1 \text { for } 1 \leq i \leq n ; \\
f\left(v_{i}\right) & =f\left(u v_{i}\right)=\left\lceil\frac{n+1}{2}\right\rceil \text { for } 1 \leq i \leq n ; \\
f\left(v_{i} w_{i}\right) & = \begin{cases}i & \text { for } 1 \leq i \leq\left\lceil\frac{n}{2}\right\rceil \\
n-i+2 & \text { for }\left\lceil\frac{n}{2}\right\rceil+1 \leq i \leq n ;\end{cases} \\
f\left(w_{i} v_{i+1}\right) & = \begin{cases}i & \text { for } 1 \leq i \leq\left\lceil\frac{n}{2}\right\rceil \\
n-i+1 & \text { for }\left\lceil\frac{n}{2}\right\rceil+1 \leq i \leq n .\end{cases}
\end{aligned}
$$

The labeling above gives the weight of vertices of $G_{n}$ as follows.

- For $n=3$,

$$
\begin{gathered}
w_{f}(u)=9 ; w_{f}\left(v_{1}\right)=6 ; w_{f}\left(v_{2}\right)=7 ; w_{f}\left(v_{3}\right)=8 ; \\
w_{f}\left(w_{1}\right)=3 ; w_{f}\left(w_{2}\right)=5 ; w_{f}\left(w_{3}\right)=4 .
\end{gathered}
$$

- For $n \geq 4$ and $n$ is odd,

$$
w_{f}(u)=\frac{n^{2}+n+2}{2}
$$




$$
\begin{aligned}
w_{f}\left(v_{i}\right) & = \begin{cases}n+3 & \text { for } i=1 \\
n+2 i & \text { for } 2 \leq i \leq\left\lceil\frac{n}{2}\right\rceil \\
3 n-2 i+5 & \text { for }\left\lceil\frac{n}{2}\right\rceil+1 \leq i \leq n\end{cases} \\
w_{f}\left(w_{i}\right) & = \begin{cases}2 i+1 & \text { for } 1 \leq i \leq\left\lceil\frac{n}{2}\right\rceil \\
2 n-2 i+4 & \text { for }\left\lceil\frac{n}{2}\right\rceil+1 \leq i \leq n .\end{cases}
\end{aligned}
$$

- For $n \geq 4$ and $n$ is even,

$$
\begin{aligned}
w_{f}(u) & =\frac{n^{2}+2 n+2}{2} ; \\
w_{f}\left(v_{i}\right) & = \begin{cases}n+4 & \text { for } i=1 \\
n+2 i+1 & \text { for } 2 \leq i \leq \frac{n}{2}+1 \\
3 n-2 i+6 & \text { for } \frac{n}{2}+2 \leq i \leq n\end{cases} \\
w_{f}\left(w_{i}\right) & = \begin{cases}2 i+1 & \text { for } 1 \leq i \leq \frac{n}{2} \\
2 n-2 i+4 & \text { for } \frac{n}{2}+1 \leq i \leq n .\end{cases}
\end{aligned}
$$

From the labeling $f$, there are no two vertices with the same weight. The maximum label used by the labeling $f$ is 3 , for $n=3$, and $\left\lceil\frac{n+1}{2}\right\rceil$, for $n \geq 4$. So that, $f$ is a vertex irregular total 3-labeling of $G_{3}$ and a vertex irregular total $\left\lceil\frac{n+1}{2}\right\rceil$-labeling of $G_{n}$ for $n \geq 4$. So, we have an inequality

$$
\operatorname{tvs}\left(G_{n}\right) \leq \begin{cases}3 & \text { for } n=3 \\ \left\lceil\frac{n+1}{2}\right\rceil & \text { for } n \geq 4\end{cases}
$$

From inequality (1) and (2), we have an equality

$$
\operatorname{tvs}\left(G_{n}\right)= \begin{cases}3 & \text { for } n=3 \\ \left\lceil\frac{n+1}{2}\right\rceil & \text { for } n \geq 4\end{cases}
$$

\subsection{On The Total Edge and Vertex Irregularity Strength of Fungus}

The results on this subsection give the total edge irregularity strength and the total vertex irregularity strength of fungus.

Let $n \geq 3$, fungus $F g_{n}$ is a graph with the vertex set $V\left(F g_{n}\right)=\left\{u, v_{1}, v_{2}, \cdots, v_{2 n}\right\}$ and the edge set $E\left(F g_{n}\right)=\left\{u v_{i} \mid 1 \leq i \leq 2 n\right\} \cup\left\{v_{i} v_{i+1} \mid n+1 \leq i \leq 2 n-1\right\} \cup$ $\left\{v_{2 n} v_{n+1}\right\}$.

The theorem below gives the total edge irregularity strength of fungus.

Theorem 2.3. Let $n \geq 3$ and $F g_{n}$ be a fungus with order $2 n+1$. Then,

$$
\operatorname{tes}\left(F g_{n}\right)=n+1 \text {. }
$$

Proof. Fungus $F g_{n}$ is a graph with $3 n$ edges. Theorem 1.1 gives that a lower bound on $\operatorname{tes}\left(F g_{n}\right)$ is $\left\lceil\frac{3 n+2}{3}\right\rceil=n+1$. 
Let $f: V\left(F g_{n}\right) \cup E\left(F g_{n}\right) \rightarrow\{1,2, \cdots, n+1\}$ be a total labeling of $F g_{n}$ such that

$$
\begin{aligned}
f(u) & =1 ; \\
f\left(v_{i}\right) & = \begin{cases}1 & \text { for } 1 \leq i \leq n \\
n+1 & \text { for } n+1 \leq i \leq 2 n\end{cases} \\
f\left(u v_{i}\right) & = \begin{cases}i & \text { for } 1 \leq i \leq n \\
i+1-n & \text { for } n+1 \leq i \leq 2 n ;\end{cases} \\
f\left(v_{i} v_{i+1}\right) & =2 n+2-i \text { for }, n+1 \leq i \leq 2 n-1 ; \\
f\left(v_{2 n} v_{n+1}\right) & =2 .
\end{aligned}
$$

The weight of edges of $F g_{n}$ under the labeling $f$ above is as follows.

$$
\begin{aligned}
w_{f}\left(u v_{i}\right) & = \begin{cases}2+i & \text { for } 1 \leq i \leq n \\
3+i & \text { for } n+1 \leq i \leq 2 n\end{cases} \\
w_{f}\left(v_{i} v_{i+1}\right) & =4 n+4-i \text { for } n+1 \leq i \leq 2 n-1 ; \\
w_{f}\left(v_{2 n} v_{n+1}\right) & =2 n+4 .
\end{aligned}
$$

Every two distinct edges have two distinct weights. So, $f$ is an edge irregular total $(n+1)$-labeling of $F g_{n}$ and we can conclude that $\operatorname{tes}\left(F g_{n}\right)=n+1$.

The next theorem gives the total vertex irregularity strength of fungus.

Theorem 2.4. Let $n \geq 3$ and $F g_{n}$ be a fungus with order $2 n+1$. Then,

$$
\operatorname{tvs}\left(F g_{n}\right)=\left\lceil\frac{n+1}{2}\right\rceil \text {. }
$$

Proof. Fungus $F g_{n}$ has $2 n+1$ vertices, which are $n$ vertices with degree $1, n$ vertices with degree 3 , and 1 vertex with degree $2 n$. By using Theorem 1.4, we have $\operatorname{tvs}(G) \geq \max \left\{\left\lceil\frac{1+n}{2}\right\rceil,\left\lceil\frac{1+n+n}{2+2}\right\rceil,\left\lceil\frac{1+n+n+1}{2 n+1}\right\rceil\right\}=\left\lceil\frac{n+1}{2}\right\rceil$. So, we have an inequality

$$
\operatorname{tvs}\left(F g_{n}\right) \geq\left\lceil\frac{n+1}{2}\right\rceil, \text { for } n \geq 3 \text {. }
$$

Next, we will show that $\operatorname{tvs}\left(F g_{n}\right) \leq\left\lceil\frac{n+1}{2}\right\rceil$ for $n \geq 3$. Define a total labeling $f$ of $F g_{n}$ as follows.

$$
\begin{aligned}
& f(u)=1 \\
& f\left(v_{i}\right)=\left\{\begin{array}{lc}
\left\lceil\frac{i}{2}\right\rceil & \text { for } 1 \leq i \leq n \\
\left\lceil\frac{n+1}{2}\right\rceil-1 & \text { for } i=n+1 \\
\left\lceil\frac{n+1}{2}\right\rceil & \text { for } i=n+\left\lfloor\frac{n}{2}\right\rfloor+1 \text { and } \\
\left\lceil\frac{n+1}{2}\right\rceil-1 & (n \equiv 1(\bmod 4) \text { or } n \equiv 2(\bmod 4)) \\
\left\lceil\frac{n+1}{2}\right\rceil & (n \equiv 3(\bmod 4) \text { or } n \equiv 0(\bmod 4))
\end{array}\right.
\end{aligned}
$$




$$
\begin{aligned}
& f\left(u v_{i}\right)= \begin{cases}\left\lceil\frac{i+1}{2}\right\rceil & \text { for } 1 \leq i \leq n \\
\left\lceil\frac{n+1}{2}\right\rceil & \text { for } n+1 \leq i \leq 2 n\end{cases} \\
& f\left(v_{i} v_{i+1}\right)= \begin{cases}2\left\lceil\frac{i-n}{2}\right\rceil-1 & \text { for } n+1 \leq i \leq n+\left\lfloor\frac{n}{2}\right\rfloor \\
n-\left\lfloor\frac{n}{2}\right\rfloor & \text { for } i=n+\left\lfloor\frac{n}{2}\right\rfloor+1 \text { and } n \text { odd } \\
2\left\lceil\frac{n+2}{4}\right\rceil-1 & \text { for } i=n+\frac{n}{2}+1 \text { and } n \text { even } \\
2 n-i+1 & \text { for } n+\left\lfloor\frac{n}{2}\right\rfloor+2 \leq i \leq 2 n-1 ;\end{cases} \\
& f\left(v_{2 n} v_{n+1}\right)=1 .
\end{aligned}
$$

The labeling above gives the weight of vertices of $F g_{n}$ as follows.

$$
\begin{aligned}
& w_{f}(u)=\left\{\begin{array}{ll}
\left(\frac{n+1}{2}\right)\left(\frac{n+1}{2}+n+1\right) \quad \text { for } n \text { odd } \\
\left(\frac{n+2}{2}\right)\left(\frac{n+2}{2}+n\right) & \text { for } n \text { even; }
\end{array} w_{f}\left(v_{i}\right)= \begin{cases}i+1 & \text { for } 1 \leq i \leq n \\
n+2 & \text { for } i=n+1 \text { and } n \text { odd } \\
n+3 & \text { for } i=n+1 \text { and } n \text { even } \\
2 i-n-1 & \text { for } n+2 \leq i \leq n+\left\lceil\frac{n}{2}\right\rceil \text { and } n \text { odd } \\
2 i-n & \text { for } n+2 \leq i \leq n+\frac{n}{2} \text { and } n \text { even } \\
2 n+2 & \text { for } i=n+\frac{n}{2}+1 \text { and } n \equiv 2(\bmod 4) \\
2 n+1 & \text { for } i=n+\frac{n}{2}+1 \text { and } n \equiv 0(\bmod 4) \\
2 n+1 & \text { for } i=n+\frac{n}{2}+2 \text { and } n \equiv 2(\bmod 4) \\
2 n+2 & \text { for } i=n+\frac{n}{2}+2 \text { and } n \equiv 0(\bmod 4) \\
2(2 n-i)+n+4 & \text { for } n+\left\lceil\frac{n}{2}\right\rceil+1 \leq i \leq 2 n \text { and } n \text { odd } \\
2(2 n-i)+n+5 & \text { for } n+\frac{n}{2}+3 \leq i \leq 2 n \text { and } n \text { odd; }\end{cases} \right.
\end{aligned}
$$

It can be seen that under the labeling $f$, there are no two vertices with the same weight. The maximum label of $f$ is $\left\lceil\frac{n+1}{2}\right\rceil$. So that, $f$ is a vertex irregular total $\left\lceil\frac{n+1}{2}\right\rceil$-labeling of $F g_{n}$. So, we can conclude that $\operatorname{tvs}\left(F g_{n}\right) \leq\left\lceil\frac{n+1}{2}\right\rceil$ for $n \geq 3$.

So that, we have an exact value of $\operatorname{tes}\left(F g_{n}\right)$ as follows.

$$
\operatorname{tvs}\left(F g_{n}\right)=\left\lceil\frac{n+1}{2}\right\rceil \text { for } n \geq 3 \text {. }
$$

\subsection{On The Total Edge and Vertex Irregularity Strength of of Some Copies of Star}

In this section, we give the total edge irregularity strength and the total vertex irregularity strength of $m$ copies of star.

Theorem 2.5. Let $m S_{n}$ be $m$ copies of star $S_{n}$. Then, for $n, m \geq 2$,

$$
\text { tes }\left(m S_{n}\right)=\left\lceil\frac{m n+2}{3}\right\rceil \text {. }
$$

Proof. Let $S_{n}, n \geq 2$, be a star with order $n+1$ and $m S_{n}, m \geq 2$, denotes $m$ copies of $S_{n}$. Let $V\left(m S_{n}\right)=\left\{v_{i, j} \mid 1 \leq i \leq n, 1 \leq j \leq m\right\} \cup\left\{v_{0, j} \mid 1 \leq j \leq m\right\}$ be a vertex 
set of $m S_{n}$ and $E\left(m S_{n}\right)=\left\{e_{i, j}=v_{0, j} v_{i, j} \mid 1 \leq i \leq n, 1 \leq j \leq m\right\}$ be an edge set of $m S_{n}$.

The graph $m S_{n}$ has $m n$ edges. By using Theorem 1.1, we have tes $\left(m S_{n}\right) \geq\left\lceil\frac{m n+2}{3}\right\rceil$. Next, we will show that $\operatorname{tes}\left(G_{n}\right) \leq\left\lceil\frac{m n+2}{3}\right\rceil$. Define a total $\left\lceil\frac{m n+2}{3}\right\rceil$-labeling

$$
f: V\left(m S_{n}\right) \cup E\left(m S_{n}\right) \rightarrow\left\{1,2, \cdots,\left\lceil\frac{m n+2}{3}\right\rceil\right\}
$$

of $m S_{n}$ as follows.

(1) For $j=1$,

$$
f\left(v_{0,1}\right)=1 ; \quad f\left(v_{i, 1}\right)=\left\lceil\frac{i+1}{2}\right\rceil ; \quad f\left(e_{i, 1}\right)=\left\lfloor\frac{i+1}{2}\right\rfloor, 1 \leq i \leq n .
$$

(2) For $2 \leq j \leq m$,

(a) For $i=0$,

$$
f\left(v_{i, j}\right)=\left\lceil\frac{j n+2}{3}\right\rceil,
$$

(b) For $1 \leq i \leq n$, the labeling is partitioned to some cases as follows.

- For $n \equiv 0(\bmod 6)$,

$$
\begin{aligned}
& f\left(v_{i, j}\right)=\left\lceil\frac{j n}{3}\right\rceil-\frac{n-2}{2}+\left\lceil\frac{i-1}{2}\right\rceil ; \\
& f\left(e_{i, j}\right)=\left\lceil\frac{j n}{3}\right\rceil-\frac{n-2}{2}+\left\lfloor\frac{i-1}{2}\right\rfloor .
\end{aligned}
$$

- For $n \equiv 3(\bmod 6)$,

$$
\begin{aligned}
& f\left(v_{i, j}\right)=\left\lceil\frac{j n}{3}\right\rceil-\frac{n-3}{2}+\left\lfloor\frac{i-1}{2}\right\rfloor ; \\
& f\left(e_{i, j}\right)=\left\lceil\frac{j n}{3}\right\rceil-\frac{n-3}{2}+\left\lfloor\frac{i-2}{2}\right\rfloor .
\end{aligned}
$$

- For $n \equiv 1(\bmod 6)$ or $n \equiv 5(\bmod 6)$,

$$
\begin{aligned}
& f\left(v_{i, j}\right)= \begin{cases}\left\lceil\frac{j n+1}{3}\right\rceil-\frac{n-1}{2}+\frac{i-1}{2} & \text { for } i \text { odd } \\
\left\lceil\frac{j n}{3}\right\rceil-\frac{n-3}{2}+\frac{i-2}{2} & \text { for } i \text { even; }\end{cases} \\
& f\left(e_{i, j}\right)= \begin{cases}\left\lceil\frac{j n}{3}\right\rceil-\frac{n-1}{2}+\frac{i-1}{2} & \text { for } i \text { odd } \\
\left\lceil\frac{j n+1}{3}\right\rceil-\frac{n-1}{2}+\frac{i-2}{2} & \text { for } i \text { even. }\end{cases}
\end{aligned}
$$

- For $n \equiv 2(\bmod 6)$ or $n \equiv 4(\bmod 6)$,

$$
\begin{aligned}
& f\left(v_{i, j}\right)= \begin{cases}\left\lceil\frac{j n}{3}\right\rceil-\frac{n-2}{2}+\frac{i-1}{2} & \text { for } i \text { odd } \\
\left\lceil\frac{j n+1}{3}\right\rceil-\frac{n-2}{2}+\frac{i-2}{2} & \text { for } i \text { even; }\end{cases} \\
& f\left(e_{i, j}\right)= \begin{cases}\left\lceil\frac{j n+1}{3}\right\rceil-\frac{n}{2}+\frac{i-1}{2} & \text { for } i \text { odd } \\
\left\lceil\frac{j n}{3}\right\rceil-\frac{n-2}{2}+\frac{i-2}{2} & \text { for } i \text { even. }\end{cases}
\end{aligned}
$$


From the formula of labeling above, it can be checked that the maximum label used in the labeling $f$ is $\left\lceil\frac{m n+2}{3}\right\rceil$.

The labeling $f$ above gives the weight of edges of $m S_{n}$ as follows.

(1) For $j=1$,

$$
w_{f}\left(e_{i, 1}\right)=i+2 \text {, for } 1 \leq i \leq n \text {. }
$$

(2) For $2 \leq j \leq m$ and $1 \leq i \leq n$, the weight of edges $e_{i, j}$ is as follows.

- For $n \equiv 0(\bmod 6)$ or $n \equiv 3(\bmod 6)$,

$$
w_{f}\left(e_{i, j}\right)=n(j-1)+i+2 .
$$

- For $n \equiv 1(\bmod 6), n \equiv 2(\bmod 6), n \equiv 4(\bmod 6)$ or $n \equiv 5(\bmod 6)$,

$$
w_{f}\left(e_{i, j}\right)=\left\lceil\frac{j n+2}{3}\right\rceil+\left\lceil\frac{j n+1}{3}\right\rceil+\left\lceil\frac{j n}{3}\right\rceil-n+i .
$$

From the formula above, it can be checked that there are no two edges with the same weight. So, $f$ is an edge irregular total $\left\lceil\frac{m n+2}{3}\right\rceil$-labeling of $m S_{n}$ for $m \geq 2$ and $n \geq 2$. So that, tes $\left(m S_{n}\right)=\left\lceil\frac{m n+2}{3}\right\rceil$.

The last theorem below gives the total vertex irregularity strength of $m$ copies of star.

Theorem 2.6. Let $m S_{n}$ be $m$ copies of star $S_{n}, n, m \geq 2$. Then,

$$
\operatorname{tvs}\left(m S_{n}\right)=\left\lceil\frac{m n+1}{2}\right\rceil \text {. }
$$

Proof. The graph $m S_{n}$ with order $(n+1) m$ has $m n$ vertices with degree $\delta\left(m S_{n}\right)=1$ and $m$ vertices with degree $\Delta\left(m S_{n}\right)=n$. By using Theorem 1.4, we have

$$
\operatorname{tvs}\left(m S_{n}\right) \geq \max \{\lceil(1+m n) / 2\rceil,\lceil(1+m n+m) /(n+1)\rceil\}=\lceil(m n+1) / 2\rceil .
$$

Define $k=\lceil(1+m n) / 2\rceil$. To show that $k$ is an upper bound on $\operatorname{tvs}\left(m S_{n}\right)$, define a total $k$-labeling $f: V\left(m S_{n}\right) \cup E\left(m S_{n}\right) \rightarrow\{1,2, \ldots, k\}$ such that for every $j=$ $1,2, \ldots, m$ as follows:

$$
\begin{aligned}
& f\left(v_{0, j}\right)=k ; \\
& f\left(v_{i, j}\right)= \begin{cases}\left\lceil\frac{j}{2}\right\rceil+\frac{(i-1) m}{2} & \text { for } i \text { odd } \\
\left\lfloor\frac{j}{2}\right\rfloor+\left\lceil\frac{m+1}{2}\right\rceil+\frac{(i-2) m}{2} & \text { for } i \text { even; }\end{cases} \\
& f\left(e_{i, j}\right)= \begin{cases}\left\lfloor\frac{j}{2}\right\rfloor+\frac{(i-1) m}{2}+1, & \text { for } i \text { odd } \\
\left\lceil\frac{j}{2}\right\rceil+\left\lceil\frac{m}{2}\right\rceil+\frac{(i-2) m}{2}, & \text { for } i \text { even. }\end{cases}
\end{aligned}
$$

From the labeling $f$ above, we have the weight of vertices of $m S_{n}$ as follows.

$$
\begin{aligned}
& w_{f}\left(v_{i, j}\right)=j+1+(i-1) m, \text { for } 1 \leq i \leq n, 1 \leq j \leq m \\
& w_{f}\left(v_{0, j}\right)=\left\{\begin{array}{c}
k+\left(\frac{n-1}{2}\right)\left(j+m+\left\lceil\frac{m}{2}\right\rceil+1\right)+\left\lfloor\frac{j}{2}\right\rfloor+1+\frac{m(n-3)(n-1)}{4} \\
\text { for } n \text { odd } \\
k+\left(\frac{n}{2}\right)\left(j+\left\lceil\frac{m}{2}\right\rceil+1\right)+\frac{m(n-2)(n)}{4} \\
\quad \text { for } n \text { even }
\end{array}\right.
\end{aligned}
$$


It can be checked that the maximum label used in the labeling $f$ of $m S_{n}$ is $k$. Beside that, there are no two vertices with the same weight. So that, $\operatorname{tvs}\left(m S_{n}\right)=$ $k=\lceil(1+m n) / 2\rceil$.

\section{REFERENCES}

[1] M. Bača, S. Jendrol̆, M. Miller, and J. Ryan, "On irregular total labelings", Discrete Mathematics, 307 (2007), 1378-1388.

[2] Nurdin, E. T. Baskoro, A. N. M. Salman, and N. N. Gaos, "On the total vertex irregularity strength of trees", Discrete Math., 310 (2010), 3043-3048.

[3] Nurdin, E. T. Baskoro, and A. N. M. Salman, "The total edge irregular strengths of union graphs of $K_{2, n} "$, J. Mat. Sain., 11(3) (2006), 106-110.

[4] Nurdin, A. N. M. Salman, and E. T. Baskoro, "The total edge-irregular strengths of the corona product of paths with some graphs", J. Combin. Math. Combin. Comput., 65 (2008), $163-175$.

[5] Nurdin, "On the total vertex irregularity strengths of quadratrees and banana trees", $J$. Indones. Math. Soc., 18 (2012), 31-36.

[6] Nurdin, E. T. Baskoro, A. N. M. Salman, and N. N. Gaos, "On the total vertex irregular labellings for several types of trees", Utilitas Mathematica, 83 (2010), 277-290.

[7] Nurdin, E. T. Baskoro, A. N. M. Salman, and N. N. Gao,s "On the total vertex irregular strength of a disjoint union of t copies of a path", Journal of Combinatorial Mathematics and Combinatorial Computing, 71 (2009), 227-233.

[8] J. Przybylo, "Linear bound on the irregularity strength and the total vertex irregularity strength of graphs", SIAM J. Discrete Math., 23 (2009), 511-516.

[9] M. K. Siddiqui, A. Ahmad, M. F. Nadeem, and Y. Bashir, "Total edge irregularity strength of the disjoint union of sun graphs", International Journal of Mathematics and Soft Computing, 3 (2013), 21-27.

[10] C. Tong and X. Lin and Y. Yang and L. Wang, "Irregular total labellings of $C_{m} \square C n$ ", Util. Math., 81 (2010), 3-13.

[11] K. Wijaya and Slamin, "Total vertex irregular labeling of wheels, fans, suns and friendship graphs", J. Combin. Math. Combin. Comput., 65 (2008), 103-112. 